\title{
The Ethical Unconscious: From Freud to Lacan
}

Psychoanalysis has always been fascinated with the sublimation of aggression in language, and by extension with the sublimation of aggression in the subject, especially given Lacan's view that the subject is a signifier for other signifiers. Lacan's unique contribution to psychoanalysis has been to describe aggression and sexuality in terms of a language of the self, positing a fundamental similarity between linguistic structure and the unconscious. More specifically, Lacan argues that the status of the unconscious, which is structured like a language, is ethical, and consequently one may ask in what ways Lacanian theory does and does not elaborate the relation between psychoanalysis and ethics. ${ }^{1}$

Following the late Freud, Lacan places aggressivity in the forefront of psychoanalysis, and in this preoccupation with aggressivity lies psychoanalysis's greatest intimacy with ethics.

1. General references to Freud and Lacan will be given parenthetically in the text. They include Sigmund Freud, The Standard Edition, ed. James Strachey, 24 vols. (London: Hogarth, 1953-74); Jacques Lacan, Ecrits: A Selection, trans. Alan Sheridan (New York: Norton, 1977), Encore (Paris: Seuil, 1975), De la psychose paranoïaque (Paris: Seuil, 1975), The Four Fundamental Concepts of Psychoanalysis, trans. Alan Sheridan (New York: Norton, 1981), and L'Ethique de la psychanalyse (Paris: Seuil, 1986). Translations, unless otherwise indicated, are mine. 
Moral philosophy has strived traditionally to resolve conflicts, and psychoanalysis, when it takes aggression as its object, allies itself with this tradition. Indeed, the transference of the analytic session, according to Freud, transforms "pathogenic conflict into a normal one for which it must be possible somehow to find a solution" (16:435). The analyst may thus "expect to lead the revived conflict to a better outcome" (16:438). Although Freud refers specifically to conflict, it is Lacan who gives aggressivity more substance. Indeed, in Lacan, aggressivity is constitutive of the subject. The theory of the mirror phase reveals aggression to be at the heart of subjectivity. A network of imaginary identifications captures each self and effects an aggressive disintegration of the individual at an early age. The subject is cut into membra disjecta, as illustrated by the mutilated and partial bodies found in fantasy and art. Lacan points to Hieronymous Bosch's paintings as "an atlas of all the aggressive images that torment mankind" (Ecrits 11). The fragmented nature of the subject also comes to light in fantasies of the fortified self, symbolized in dreams by images of castles, stadiums, and inner enclosures. The imaginary phase inserts the subject in a line of fiction that prefigures the later splitting of the ego as it accedes to language and falls under the sway of symbolic mediations.

More significant, however, the mirror phase situates the play of aggressivity in relation to primary narcissism. Later instances of intersubjective rivalry are referred to self-aggression because the narcissistic perspective maintains an identity between self and objects. The phenomenon known as transitivism, of which Freud's "A Child Is Being Beaten" provides a fine example, demonstrates the strictness of narcissistic identifications. "The child who strikes another says he has been struck," observes Lacan, and "the child who sees another fall, cries" (Ecrits 19). The subject's aggression toward an object similarly refers to an essential self-aggression.

The analytic session represents another kind of mirror phase, but exists to lay bare the fact of the patient's self-aggression. Analysands in Lacan's view strive to complete themselves by coming to grips with the aggression that threatens the unity of subjectivity. The flow of speech directed toward the analyst is 
the venom of aggressivity, whereas any pretense of altruism on the part of the doctor conceals intense desires and self-interests. The analytic session risks turning into a mock battlefield, where analyst and analysand seek to capture each other in an action of warfare against themselves.

Lacan seems at first glance to push sexuality into the background. The sexual relation cannot be the end of analysis. Nor does Lacan find it inscribed in the unconscious. ${ }^{2}$ The early paper "Aggressivity in Psychoanalysis" gives great prominence to aggression, and elsewhere Lacan admits that he has been accused of ignoring sexuality. The accusation arises in part from the emphasis on structure and language made so familiar by the formula "The unconscious is structured like a language." Yet the charge may also derive from Lacan's insistence on the aggression of subjectivity. The influence of Hegel and Kojève in Lacan's work encourages one to read him in terms of identification and of the struggle between master and slave; and even when one proceeds carefully, desire seems a question more of identity and aggression than of sexuality.

Freud's own attitude toward aggression has a complicated history. He resisted recognizing an aggressive instinct until the end of his life because he feared that it would monopolize the nature of instinct in general. Yet from the case study of Dora, where he recognizes aggression as integral to treatment, to Jokes and Their Relation to the Unconscious, where he links hostility and obscenity as the only true purposes of jokes, and finally to $B e$ yond the Pleasure Principle, where the idea of the death drive reaches its perfection, aggression grows in importance for Freud and eventually moves to the center of his theory. In effect, the history of psychoanalysis may also be considered the history of Freud's discovery of an aggressive impulse, the death drive, and his attempt to reconcile it with sexuality. The history moves from Freud's early interest in the traumatic nature of sexuality to his recognition of the death drive-the moment when Eros and Death embrace. Lacan, who need only return to Freud, begins

2. See Jacques-Alain Miller, "Another Lacan," Lacan Study Notes 1.3 (1984): $1-3$. 
with this embrace. Freud's work opens with sexuality and tends toward a theory of aggression, whereas Lacan begins with aggression and identification and increasingly brings them into relation with sexuality. Lacan repeats Freud, but he differs in something essential: he repeats the path of subjectivity, stressing in his attempt to relate aggression and sexuality certain ethical implications only suggested by Freud.

\section{Proton Pseudos}

In the Project of 1895, Freud asks what special attribute of sexuality makes it alone subject to repression. The question engenders a search for memories, a quest for scenes, that leads ultimately to a primal scene.

In hysteria, Freud discovers, the patient displays an seemingly inappropriate response to a situation or sensation. She traces the origin of her compulsive behavior to a memory, but remembering the scene has no effect on her fears, nor does it seem to provide a sufficient cause for the symptoms. Hysterical repression takes the form of a proton pseudos, a series of false conclusions based on false premises, which serves to conceal from consciousness the traumatic scene responsible for the patient's illness. More specifically, before analysis, a scene A forces its way into the patient's consciousness and causes an affect, but the patient finds it ridiculous that A should be disturbing. Analysis uncovers a scene $B$ that justifies the patient's response, but $B$ has remained hidden in the unconscious. As Freud explains it, "B was appropriate for producing the lasting effect. The reproduction of this event in memory has now taken a form of such a kind that it is as though A has stepped into B's place. A has become a substitute, a symbol for B. Hence the incongruity: $\mathrm{A}$ is accompanied by consequences which it does not seem worthy of, which do not fit in with it" (1:349).

Freud notes that the normal formation of symbols occurs in the same way. Soldiers sacrifice themselves for a scrap of cloth on a pole, called a flag, and knights have entered into combat over a lady's glove. But the knowledge of symbol formation in hysteria is different: "The knight who fights for his lady's glove 
knows ... that the glove owes its importance to the lady. ... The hysteric, who weeps at $A$, is quite unaware that he is doing so on account of the association $A-B$, and $B$ itself plays no part at all in his psychical life" (1:349).

It may be an understatement to conclude that the originary scene plays no part in the patient's psychical life, for it is precisely its repression that orients the individual's illness. The repression is incomplete, however, as repression always is. Although the second scene $(\mathrm{A})$ is an interpretation of the repressed scene (B), it remains available to memory. The originary scene is repressed from consciousness, but its interpretation is not. The second scene signifies the earlier one, but also carries a later interpretation of the first, thereby accounting for the incongruity between the second scene and its effects. More precisely, the interpretation of the first scene is of a sexual nature, whereas the second scene appears to have no relation to sexual desires.

The case of Emma reported by Freud in the Project may serve to clarify the idea of the proton pseudos and to introduce the role played by aggression in symbol formation. Freud recounts that Emma suffers from a compulsion of not being able to go into shops alone. As an explanation, she reports a memory from age twelve, in which two shop assistants laughed at her and she fled with a feeling of fright. She also recalls that the two were laughing at her clothes and that one of them was sexually attractive to her. Further analysis, however, reveals an earlier memory. When Emma was eight years old, she entered a small shop to buy some sweets, and the shopkeeper took hold of her genitals through her clothing. Freud describes the incident as a "sexual assault," and it has an oppressive effect on Emma's conscience. Despite her first experience with the shopkeeper, she returned to the store a second time. Later she reproached herself for returning, as if she had desired to provoke an assault. Freud traces her present mental condition to the experience and reconstructs the course of events:

In the shop the two assistants were laughing; this laughing aroused (unconsciously) the memory of the shopkeeper. Indeed, 
the situation had yet another similarity [to the earlier one] she was once again in a shop alone. Together with the shopkeeper she remembered his grabbing through her clothes; but since then she had reached puberty. The memory aroused what it was certainly not able to at the time, a sexual release, which was transformed into anxiety. With this anxiety, she was afraid that the shop-assistants might repeat the assault, and she ran away.

Freud's description of memory focuses on the sexual content contributed to the first scene by the action of the second one. According to Freud, the sexual nature of the attack is at the age of eight beyond Emma's comprehension, but once she reaches puberty, her unconscious mind reinterprets the scene correctly without fully remembering it. In the end, her traumatic experience cannot be attributed to either scene; rather, it arises as a result of the interpretive activity linking the two scenes. Freud defines this peculiar function of memory as "deferred action": "Now this case is typical of repression in hysteria. We invariably find that a memory is repressed which has only become a trauma by deferred action. The cause of this state of things is the retardation of puberty as compared with the rest of the individual's development" (1:356). Deferred action (Nachträglichkeit) cannot be contained to a specific connection between memories. It operates within the first scene and wherever the subject judges her past actions according to a new knowledge. The knowledge carries with it responsibility, and eventually turns the individual's consciousness toward itself.

It has rarely been remarked, however, that deferred action is specifically sexual. It operates at every level of memory, connecting the two scenes as Emma's sexuality emerges, but also turning her consciousness inward. In this case, the deferred action pushes Emma's awareness of her sexuality backward in time and makes her more responsible for the sexual assault. She suffers from an "oppressive bad conscience" because she returned to the shop a second time. She feels guilty about playing the seductress for the shopkeeper. Jean Laplanche, in Life and Death in Psychoanalysis, interprets Emma's role as actively seductive. He argues that nothing prevents one from asking whether she 
had come to the shop on the first occasion to be attacked, having been "moved by some obscure sexual premonition." 3 Astoundingly, Laplanche fails to offer an analysis of deferred action. Rather, his reading is itself an example of deferred action applied by the analyst, for the question is not whether Emma is prophetic but whether she now believes that she originally went to the shop for a sexual experience. Undoubtedly, she would believe Laplanche's interpretation, for it reinforces her own interpretation and seems the only explanation for her present refusal to enter a shop alone. The analyst and patient end by agreeing that sexuality holds a privileged position in memory.

The similarity between Emma's bad conscience and Laplanche's interpretation suggests that psychoanalysis tends to reinforce the subject's self-victimization. It shifts responsibility from the victimizer to the victim of abuse, making her the prime mover in her suffering. The victimary tendencies of psychoanalysis are especially obvious in its theories of masochism, particularly in the view that creates an equation between the structures of masochism and female subjectivity. This equation is only valuable because women as a class are victims, not because it cuts to the truth of female character. On the one hand, the theory further suppresses women. On the other hand, it fails to note that masochism is a logical structure directed at restoring power and self-esteem to the victimized self, at transforming it from the passive to active subject, and that as such it belongs to the subject's actions of recovery and self-preservation. Ultimately, however, this defense can only become destructive and redundant, not unlike the activity of the child in the Fort-da game, where the recuperated mastery of the boy is an illusion of self-manipulation, not a genuine recovery of selfesteem.

The two scenes of Emma's seduction nevertheless share another similarity unnoticed by either Freud or Laplanche. Both

3. Jean Laplanche, Life and Death in Psychoanalysis, trans. Jeffrey Mehlman (Baltimore: Johns Hopkins University Press, 1976), p. 39. On the issue of the victimizing impulses within Freud's theory of hysteria, cf. Jeffrey Moussaieff Masson, The Assault on Truth: Freud's Suppression of the Seduction Theory (New York: Farrar, Straus and Giroux, 1984). 
the shopkeeper and assistants behave aggressively toward Emma. Especially in the second case, the laughter of the shop assistants has an unmistakably hostile content that is all the more remarkable for the fact that Emma and Freud mistake it. For Emma, the sexual release aroused by deferred action overwhelms any other interpretation of the scene, including the meaning that most people would naturally give to it. Since Freud is searching for what Emma has already found, he follows her lead and accepts the sexual meaning.

Lacan's reading of the case, sketched in the seminar L'Ethique de la psychanalyse, is equally baffling. Like Freud, he views the convergence between the two memories as essentially repressive. In fact, Lacan attaches a special significance in this regard to the fact that Emma's second "assault" occurs in a clothing store. The old man in the candy store grabs Emma through her clothes, and the vestiges of the memory remain attached to clothing. But the fact that clothing creates the alliance of memories is belied by the fact that clothing also covers things up. The deferred action between the scenes takes on the quality of clothing one memory in the other, hiding the truth under what Lacan calls the "Vorstellung mensongère du vêtement," or the "deceitful representation of clothing" (90).

The lie of clothing is most instructive with regard to the action of deferral, but Lacan's insistence on the problem of deceit does not end by exposing the aggressivity of the early scene. Surprisingly, Lacan begins by giving more emphasis to the old man's aggression than Freud's text would actually seem to permit. He adds to Freud's account and goes to the trouble of imagining the encounter in great detail. Freud, we remember, writes that the "shopkeeper had grabbed at her genitals though her clothes" (1:354). But Lacan describes "an old man who pinched her I don't know where very directly under her dress" (90). Yet when he analyzes the incident in the clothing store, he takes it for granted that the sexual attraction that Emma feels for the clerk is an echo of the sexual feelings experienced during the pinch. Lacan exaggerates the aggressivity only to whisk it away. The translation from Lacan's imaginative version of the aggressive pinch to the sexual attraction of the later scene merely oc- 
curs, and with little reflection on the fact that the repression of aggressivity seems to undo those details that Lacan chooses most to emphasize. It appears that Lacan too follows the sexual inclinations of deferred action.

Freud does not ask Emma whether she had interpreted the original assault as sexual, but he might have, as he did in the case of another hysteric. Katharina, in the Studies on Hysteria, was attacked by her father, but she blots the scene from her memory. She suffers as a result from anxiety attacks accompanied by the vision of an awful face. At first she traces her seizures to a scene in which she discovered her father with her cousin. Eventually, Freud uncovers the seduction scene, in which the father comes to his daughter's bed in the night; and the inevitable question, the mark of deferred action, arises: "From the way in which she reported having defended herself it seems to follow that she did not clearly recognize the attack as a sexual one. When I asked her if she knew what he was trying to do to her, she replied: 'Not at the time.' It had become clear to her much later on, she said; she had resisted because it was unpleasant to be disturbed in one's sleep and 'because it wasn't nice'" (2:130).

Deferred action is not only Freud's discovery; it is his method of analysis. Deferred action serves both to infuse past scenes with a sexual content and to accord sexuality the principal role in the interpretive process. Psychoanalysis, at least in its early stages, proceeds in the same style, uncovering the sexual content in early life and establishing it as the privileged element in psychic development. The sexualizing impulses of deferred action leave little room for another form of interpretation, but they organize memories in terms of sexuality. As such, neither Emma nor Freud is able to recognize the violence in the two scenes, for any aggressivity is expressed through sexual symbolism.

Likewise, Katharina's "sexual attack" has principally an erotic content. First, the phrase "sexual attack" itself is recognized as violent only with difficulty, for the modifier "sexual" overwhelms the sense of the other term. The phrase enters the reader's consciousness in the same manner as it enters the hysteric's mind when she is in the throes of deferred action. Second, the 
erotic nature of the attack persists at a theoretical level. Freud's theory of anxiety at this time has a sexual orientation. Accordingly, "anxiety attacks" express ambivalence toward sexual experience. They express fear, but also simulate the agitation of sexual orgasm. Katharina's seizures are a fulfillment of her desire to be seduced by her father. "Go on, you silly girl, keep still. You don't know how nice it is," the father commands in order to pacify her during the attack (2:130). Her anxiety attacks obey his orders belatedly. Her vertigo and shortness of breath represent the victory of desire over repression.

Yet some elements of the experience remain untranslated by the sexualizing impulse of deferred action and continue to trouble the two hysterics. Emma refuses to go into shops alone for fear of being attacked again. Katharina's "anxiety attacks" are accompanied by the awful face, which she eventually understands to be her father's face in rage. It is not, however, the face that he makes upon being repulsed from his daughter's bed. Later, Katharina's mother discovers her husband's infidelities and enacts divorce proceedings against him. Katharina's story of her father's assault contributes to the case, and he becomes her enemy: "He kept saying that it was all my fault: if I hadn't chattered, it would never have come to a divorce. He kept threatening he would do something to me; and if he caught sight of me at a distance his face would get distorted with rage and he would make for me with his hand raised. . . . The face I always see now is his face when he was in a rage" (2:132).

In psychoanalytic language, Katharina's vision of the awful face and Emma's fear represent examples of ambivalence. But the present context reveals ambivalence to be the product of the incomplete action of deferral and its erotic impulses. The violence of the attack, now confused with sexual desire but not fully controlled by it, remains to disturb the hysterics. A more complete fusion of the violence and sexuality would define masochism, not hysteria, and in that case, Katharina's "anxiety attack" would be more pleasurable and the awful face more welcome. Emma in turn would not fear to go to shops alone, but would seek to be attacked, as Laplanche and her bad conscience charge that she had done originally. 
Freud's contention that the awful face is the sign of ambivalence reveals his concern with the relation between sexuality and memory. Katharina's vision represents the face of repression itself. Later, after The Ego and the Id, we would say it becomes the face of the superego, the agent of the death drive, expressing its anger at the sexual pleasure of the attack. Freud begins by asking why repression acts on sexuality alone and discovers that desire is the one emotion capable of outwitting repression, of recollecting past events without having to remember them. Desire is interpretation, as Lacan says in The Four Concepts, but it is also its own interpretation; and as such, desire returns irrepressibly to desire (176).

The question arises whether sexuality defeats repression or cooperates with it in matters of aggression. The case of the proton pseudos introduces this question, but can do nothing to answer it. Nor does Freud find it adequate to the task of understanding the special relation between sexuality and repression. First, further thought leads him to subvert his analyses of hysteria. As he comes to believe more strongly in the existence of infantile sexuality, deferred action becomes possible long before the advent of puberty. Emma and Katharina are already sexual beings at the time of their assaults, and their inability to understand them is now ascribed to repression, not to incomplete sexual development. Freud increasingly turns his interest to the part played by the sexual impulses of childhood in the production of neurosis. Second, Freud determines that a fantasy of seduction, not seduction itself, lies at the basis of hysteria. This new hypothesis compels him to search for a scene of fantasy, in which the subject is not the object of love but a spectator of a scene, and in which the subject only fantasizes the seduction through a complex process of identification.

\section{The Sexual Theories of Children}

The primal scene represents another situation in which sexuality and repression collide, and psychoanalysis sets out from the premise that the primal scene is traumatic. Children who happen to witness the act of sexual intercourse between their 
parents experience conflicting emotions. According to psychoanalytic theory, the scene excites the child sexually, but also provides the basis for castration anxiety. The scene is first and foremost an arena of fantasy. Freud contends that evidence of primal fantasies is usually found among neurotics and probably exists among most people.

Although Freud now situates the beginnings of sexual excitation earlier in childhood, the role of deferred action does not change. It remains predominantly sexual and, as an agent of memory, would seem to have no more chance of representing aggression than it did in the case of hysteria. The significance of the primal scene pivots after all on its sexual content. It is a sexual scene that imposes itself on the child. In the case of the Wolf Man, Freud isolates deferred action as the means by which the child enters more fully into the scene of observation: "the scene of observation of the coitus .... in its deferred action operated like a second seduction" (17:47). Deferred action plays an essential role in the activity of unconscious sexual fantasies. In fact, it seems tempting to equate deferred action with unconscious sexual fantasy itself, for deferred action represents the sexual theorizing of the unconscious in matters of the past. Speaking once more about the Wolf Man, Freud describes the child's sexual theories and their relation to deferred action: "the object of his observation was in the first instance a coitus in the normal position, which cannot fail to produce the impression of being a sadistic act, and that only after this was the position altered, so that he had an opportunity for making other observations and judgements. . . . This is simply another instance of deferred action" (17:45 n. 1).

The sexual theories of children do not differ from Freud's views, at least with regard to deferred action. Children re-create their past through sexual fantasy, and Freud seeks to prove the basis in reality of primal fantasies. Unable to demonstrate their reality, however, he proves it unnecessary to analytic theory by observing that primal fantasies have as much reality for the unconscious as genuine primal scenes. The tendency in fantasy to reconstruct the sexual history of oneself and of one's parents takes precedence over the incidental and haphazard events of 
childhood, and as such, Freud can rightly claim that primal fantasies belong to the phylogenetic memory. The proof discovers a justification in the unconscious both for the sexual theories of children and for those of psychoanalysis.

Nevertheless, Freud's discussion of the primal scene remains unique within psychoanalytic theory for its refusal to privilege sexual interpretation in one special case. As Freud remarks in the citation above, the observation of sexual intercourse by the child "cannot fail to produce the impression of being a sadistic act" (17:45 n. 1). The early article "The Sexual Theories of Children" provides the most complete description of the child's experience: "if, through some chance domestic occurrence, they become witnesses of sexual intercourse between their parents . . . children arrive in every case at the same conclusion. They adopt what may be called a sadistic view of coition . . . for the very reason that they have interpreted the act of love as an act of violence" (9:220-21).

From the outset, I should note that Freud does not mean to refer to sexual sadism in the foregoing passage. He often uses the word "sadistic" in place of "aggressive" and appears, as does Melanie Klein, to argue for the existence of a form of nonsexual sadism. Freud does admit, however, that the sadistic view of coition may contribute to a "subsequent sadistic displacement of the sexual aim" (7:196), but such is not his topic here. Rather, he is discussing the interpretive primacy given to aggression in the child's perception of the world.

Freud's account of children's sensitivity to violence is in fact astounding, especially given his belief in the interpretive superiority of desire and deferred action in general. Children, in Freud's estimation, sense an amazing variety of details. The child's "sadistic view" has great interpretive force, for it uncovers the unconscious motivations and unspoken discomforts of parents. The child's theory, Freud writes, "is correct up to a certain point; it has in part divined the nature of the sexual act and the 'sex-battle' that precedes it. . . . In many marriages the wife does in fact recoil from her husband's embraces, which bring her no pleasure, but the risk of a fresh pregnancy" (9:221). Consequently, the child receives the impression from the moth- 
er that she is defending herself against an act of violence. Furthermore, the child tends to situate local action in the context of the marriage. "At other times," Freud continues, "the whole marriage offers an observant child the spectacle of an unceasing quarrel, expressed in loud words and unfriendly gestures; so that he need not be surprised if the quarrel is carried on at night as well . . ." (9:221-22). Children soon become detectives to confirm their theories. The presence of blood in the mother's bed or underclothes proves that the father has made an assault on his wife during the night.

This last perception emphasizes the importance of aggression in the child's sexual theories. In The Interpretation of Dreams, one of Freud's patients confirms that the primal scene unfolds within a violent context. In recounting an anxiety dream about being pursued by a man with a hatchet, a twenty-seven-year-old patient recalls how his mother feared that he would be the death of his younger brother because of his proclivity to physical abuse. Freud continues, relating and commenting upon his patient's recollection by association: "While he still seemed to be occupied with the subject of violence, a recollection from his ninth year suddenly occurred to him. . . . While he pretended to be asleep ... he had heard sounds of panting and other noises ... and he had also been able to make out their position in the bed. . . He had subsumed what happened between his parents under the concept of violence and struggling; and he had sound evidence in favour of this view in the fact that he had often noticed blood in his mother's bed" $(5: 584)$.

The patient's testimony is significant because it confirms Freud's suspicions that children interpret the act of love as an act of violence. It is disturbing, however, because their interpretation is so obviously wrong. Especially for young children, the view is strangely paranoid. Where Freud is seeking to demonstrate the sexuality of early childhood, he finds that children miss the point. They do not recognize sexual activity when it is taking place before their very eyes.

In place of the disposition to sexual interpretation, Freud discovers that children possess an almost paranoid tendency to interpret the world in terms of aggression. The sexual interpre- 
tation of the scene develops later, as Freud argues in the Wolf Man case, through the agency of deferred action. At that moment the primacy of the interpretation is reversed, and the child's perception of violence turns vague, remaining only as the obscure vestige of a mistaken view, the dim recollection of some fantastic theory. The sexual interpretation takes precedence, and one might further argue that the earlier aggressive interpretation only emerges through the aid of the erotic one. Freud contends that the death drive escapes detection unless it is represented through the agency of sexuality, which may explain why it took him so many years to accept the existence of an aggressive instinct. In Civilization and Its Discontents, he says of the death drive that "we can only suspect it, as it were, as something in the background behind Eros, and it escapes detection unless its presence is betrayed by its being alloyed with Eros" (21:121). Without an agent similar to deferred action, which alloys aggression and sexuality, the violence of the primal scene would be neither stored in the unconscious nor represented to consciousness.

Freudian theory repeatedly emphasizes the power of Eros over the death drive. Eros has libido at its command, whereas the death drive has no source of energy of its own. When the two drives fuse, Eros overwhelms the death drive, except in those instances when cunning Death twists the power of Eros against itself. In such cases, however, the erotic urges still demand satisfaction. Even when aggressiveness seems to surface without sexual purpose, in the blind fury of chaos, a degree of narcissistic enjoyment accompanies the satisfaction of the instinct, for the ego revels in the assurance of its omnipotence.

The children's theory of the primal scene bears no relation to the reality behind their observations. Yet it is not the fact that they mistake the act of love for one of violence that guarantees a correct interpretation later in life. Indeed, the question arises whether the sexuality of the primal scene is at all necessary. Since the scene of "attack" must be eroticized to be represented to consciousness, a similar process would occur if the scene were not originally sexual. Sexuality is the product of interpretation, and consequently it is not a required element of the scene. 
It is the perception of aggression that fixes the child's attention. Would the scene have less impact if the father were actually beating the mother as the child believes? Not at all, for the action of deferral would still develop a sexual interpretation of the scene. In effect, we have returned to Freud's reading of the proton pseudos. It was Emma's unconscious association between the hostile actions of the shopkeeper and assistants that allowed deferred action to recover the first scene through a sexual interpretation of the second one. The recollection of the scene emerges as a sexual component is added, and the addition becomes the origin of the memory. The first and second scenes become sexual scenes, not aggressive ones, as the representation of sexuality represses the reality of violence and enters into the unconscious.

Consequently, the sexual interpretation of the primal scene is guaranteed not by its reality but by the nature of subjectivity and its essential relation to deferred action. Sexuality emerges as a drive only when the nonsexual activity of self-preservation becomes detached from its natural object. Lacan's theory that desire is a lack has this meaning. The disappearance of the object produces a moment of self-reflexivity during which sexuality emerges. The instant of self-reflexivity is an "autoeroticism," in which the subject replaces the lost object with a fantasy, thereby internalizing the object within the subject. Freud originally stresses the activity of internalizing the object in "Mourning and Melancholia," but later recognizes it as essential to all subjectivity, especially to the formation of the ego. Lacan's theory of the mirror phase begins where Freud leaves off, where the pen falls from his hand during the writing of the "Splitting of the Ego in the Process of Defence." The mirror stage identifies the phase during which the child enters into object relations, not through sexuality but through identification, and explains how the disruption of identification through separation from the object inserts the subject in a line of fiction, the configuration of desire and language, whose essentially divisive natures will henceforth dominate his or her life.

Not surprisingly, narcissism lies at the heart of the primal 
scene. The child's perception of the scene pivots on a narcissistic identification with the mother, against whom the child believes the father is directing his aggression. The violence is therefore aimed through primary identification against the child and provides the basis for castration anxiety: the drama where the child must decide between being the object of violence, through present identifications, or the violator, through a new identification with the father. The threat of castration reveals the double nature of narcissism. Indeed, narcissism is duplicitous from its inception in the myth of Narcissus to Lacan's theory of the mirror phase. ${ }^{4}$ The child's narcissistic identification with the mother is transferred through his narcissistic concern for preservation to an identification with the father. Narcissism is active at every stage of the transference. It defines the movement from primary to secondary identification. But it is most contradictory at the moment before the allegiance to the mother is abandoned. As the identifications cross, children violate themselves. They are crucified, fixed at the crossroads, as the tale of Oedipus records. And healthy children will exist at cross purposes with themselves until they enter language. Only then will the violence directed against the self be distributed according to the oppositions of language. The Other is born. The Other loves, torments, and forsakes. Eli, Eli, lama sabachthani? Lacan establishes such exemplary self-aggression as the source of intersubjective violence, and thus emerges the necessity of the analyst's drawing out the analysand's aggressivity, of being an obstacle to the further establishment of secondary identifications between patient and doctor, and of keeping the speech of the patient flowing in a symbolic bloodletting of violence.

In subjectivity, self-aggression is primary, for the subject and sexuality emerge at the moment when aggression turns into self-aggression. I do not have the space here to illustrate this process on a theoretical plane; nor is the illustration necessary, as Laplanche describes it in great detail. The essential point

4. See my history of narcissism in The Mirror of Medusa (Berkeley: University of California Press, 1983). 
remains that masochism is primary within the field of sexuality. The masochistic fantasy, in the foregoing example, occurs when children's identification with the mother allows the fantasies of their parents to assault them, to seduce them into the scene. As children identify with their mother, they introject the suffering object, fantasize the suffering object, make the object suffer inside them, and make themselves suffer. ${ }^{5}$ In terms of the primal scene, therefore, only the presence of the suffering object is important. The scene serves to traumatize the child, introducing the moment of primary masochism, during which aggression becomes self-aggression and the "attack" is eroticized as it is repressed. Psychoanalysis sets out from the trauma of the primal scene because it alone explains the traumatic nature of sexuality, but the trauma makes no sense unless it is viewed within the context of another relation between sexuality and aggression: that sexuality represents aggression, and that behind the repression of sexuality lies another form of repression, in which sexuality and the unconscious cooperate to exclude the reality of violence. ${ }^{6}$

\section{Encore at Last}

In The Four Concepts, Lacan takes for granted that his readers understand the meaning of the phrase "the unconscious is structured like a language" (20). Yet he still makes an effort to dispute the charge that his view of the unconscious is not strictly Freudian and that he may have betrayed Freud in his embrace of linguistic structuralism. Lacan admits only one difference in em-

5. See Laplanche's explanation, p. 97.

6. Within a Lacanian register, the phrase "reality of violence" may cause some confusion. What I am trying to describe is the tendency on the part of the unconscious to represent violence in a sexual manner. It could be argued that violence therefore belongs to the Real-that which cannot be representedsince the Real serves as the zero point of death or what Lacan calls the "mystery of the unconscious" (Encore, p. 118). I am arguing, however, not for the (un)reality of violence in this sense, but for its status as an element opposed to sexuality, an element that the unconscious struggles to incorporate whenever it is encountered. This incorporation implies a representation of violence that represses it, but clearly not in the derogatory sense sometimes given to "repression." Rather, it defines the unconscious as ethical. 
phasis: "If I am formulating here that the status of the unconscious is ethical . . . it is precisely because Freud himself does not stress it when he gives the unconscious its status" (34). He further suggests that it is linguistic structure that gives the unconscious its ethical status.

Lacan discusses the ethics of psychoanalysis at great length, but his most revealing statements appear in Encore. It is true that Lacan devoted his 1959-1960 seminar to L'Ethique de la psychanalyse, but he was reluctant to publish it. He seemed to fear that it was incomplete, an idea already expressed in the opening statement of the seminar, where he decides to leave open the question of knowing what will be included under the topic. In Encore, Lacan returns to the question of knowing, and his opening remarks there recall his L'Ethique: "It has happened that I have not published L'Ethique de la psychanalyse. . . . With time, I have understood that I could say a little more about it. And then, I perceived that what was directing my path was of the order of the I want to know nothing about it" (9).

The Ecstasy of Saint Theresa by Bernini appears on the cover of Encore. It is the supreme emblem of the "I want to know nothing about it," and as such it orients the reading of the seminar. Bernini's sculpture begins by situating wanting to know nothing in relation to a collision between sexuality and aggression, and it provides a version of the primal scene in which the unconscious relation between sexuality and violence reveals its ethical dimension. In fact, we must ask whether the Wolf Man had a similar image in mind when he described his vision of the primal scene to Freud: "He assumed to begin with, he said, that the event of which he was a witness was an act of violence, but the expression of enjoyment which he saw on his mother's face did not fit in with this; he was obliged to recognize that the experience was one of gratification" (17:45). The Wolf Man, Freud notes, changes his interpretation through deferred action, and Bernini's Saint Theresa provides a vivid image of the process. It is a superb illustration of the choice in identification that the little spectator (or any spectator) of the scene must make. The scene intrudes upon spectators, asking them to identify with either the dangerous ecstasy of Saint Theresa or the sexual glory of the 
infant angel. This is a choice after the fact, however, for the inclusion of the child in the scene demonstrates that the decision has been made. The child occupies the place of the father and takes up the golden arrow, remarkable in itself for its unnaturalness in comparison with the figures in stone. The arrow is placed after the fact in the hands of the angelic child. It is a symbol of power, but a symbol that can be removed from his possession, for it is not part of his natural substance.

The scene is principally one of intimidation, and it convinces the spectator aggressively and sexually in a way that the analyst refuses to convince his patient. The patient's demand to know what he wants is too heavy for him to bear, and he prefers to know nothing about it. He would prefer to faint in ecstasy at the analyst's feet and be convinced, as God convinces Saint Theresa: "The pain was so great that I screamed aloud; but at the same time I felt such infinite sweetness that I wished the pain to last forever. It was not physical but psychic pain, although it affected the body as well to some degree. It was the sweetest caressing of the soul by God."7 The Wolf Man, for example, is in analysis because he has chosen to remain in the position of the mother. But to the patient's demand to take Saint Theresa's place, to want to know nothing, Lacan responds that he wants to know nothing about it. Although he is the subject who is supposed to know, he knows nothing in reality. Finally, it is the mutual want to know nothing, Lacan explains in Encore, that brings the analyst and analysand together again and again.

The doctor and patient both demand an encore, and this act of repetition would seem to strike to the heart of the ethics of psychoanalysis. For Lacan, the refusal to stop the flow of speech overwhelms each conclusion, each interpretation, with the demand for an encore of more interpretation. "The universe," he remarks, "is a flower of rhetoric. This literary echo could perhaps help us understand that the self can also be a flower of rhetoric. It grows from the pot of the pleasure principle, which Freud calls Lustprinzip, and which I define as that which is satis-

7. Cited by H. W. Janson, History of Art (Englewood Cliffs, N.J.: PrenticeHall, 1974), p. 412. 
fied by blablabla. This is what I mean when I say that the unconscious is structured like a language" (Encore 53).

On the one hand, the temptation exists to interpret the ethical orientation of the analytic experience in terms of pluralism. The analyst encourages freedom of speech, thereby confronting the subject's desire to have his or her freedom limited. (The greatest threat to analysis is simply to give patients what they want.) As such, the theory of the unconscious would seem the very expression of critical pluralism. The unconscious does not create boundaries between the outside and inside. It refuses to say "No!" It only replies "Yes!" and "Encore!" Lacan's own reluctance to publish his $L^{\prime}$ Ethique appears to obey this imperative and thus to swerve away from a more significant formulation of the relation between the unconscious and ethics. The seminar responds to each ethical theory, seemingly conclusive, with the encore of endless interpretation. Each theory is met with the humorously black and cynical phrase "One more time!" The ethical act comes to represent the play of purposeful incompleteness, what Lacan calls blablabla, in its refusal to convince, to name, to stop.

On the other hand, when Lacan endorses or is used to endorse the play of the signifier, as Jacques-Alain Miller asserts, it completely disorients the ethical path of the analytic experience. ${ }^{8}$ The ethical aim of psychoanalysis is to save the patient from dependency, not to force independence upon him. Freud's phrase "Wo es war, soll ich werden" charts the path of the analytic experience. Lacan renders the line as "Wherever it was, I must go there" and discusses it in terms of Freud's ethical orientation. ${ }^{9}$ Freud aims to progress from the repressed material of the unconscious ("Wherever it was") to a self free of depen-

8. Miller, "Another Lacan," p. 3.

9. For Lacan's commentary on the phrase, see The Four Concepts, p. 33, L'Ethique de la psychanalyse, p. 16, and "Compte rendu avec interpolations du Séminaire de l'Ethique," Ornicar? 28 (1984): 7-18, esp. 9-10. See also Catherine Clément, The Lives and Legends of Jacques Lacan, trans. Arthur Goldhammer (New York: Columbia University Press, 1983), pp. 145-46; Michel de Certeau, "Lacan: An Ethics of Speech," trans. Marie-Rose Logan Representations 3 (1983): 21-39, esp. 35; and Mikkel Borch-Jacobsen, "The Freudian Subject, From Politics to Ethics," October 39 (1986): 109-27. 
dency, including the excessive defensiveness of the ego ("I must go there").

Nevertheless, the analyst's policy of nonintervention rings of an altruism that Lacan himself does not permit to exist. Lacan's anti-altruism risks distorting the sense given to the idea of the "ethical unconscious" by couching it not in terms of ethical behavior but merely in terms of "character" or "personality." Ethics would be but another way to refer to subjectivity. The analyst's altruism in Lacan's eyes conceals only his own unconscious desires, and as such every nonintervention must come to represent a strategy designed to intimidate. Psychoanalytic theory, when driven to this point, always risks becoming a mere echo of the unconscious, for like the ego, it is not the master in its own house. Either the unconscious has no ethical status, and psychoanalysts delude themselves when they pretend to speak about ethics, or the unconscious permits, indeed provides the source for, the ethical aims of the analytic experience. A third option is to abandon the current theory of the unconscious altogether.

Given that Lacan admits the ethical status of the unconscious, it seems odd that he hesitated to publish L'Ethique de la psychanalyse. "I prevented this Ethique from appearing," he confesses. "I refused because I do not seek to convince people who do not want anything to do with me. Il ne faut pas convaincre. Le propre de la psychanalyse, c'est de ne pas vaincre, con ou pas" (Encore 50). The last few phrases are difficult to translate because of the wordplay. I render them as follows: "One must not convince. The nature of psychoanalysis is not to vanquish, sexually or otherwise." The translation is inadequate, but it makes my point. The passage is central to the history of psychoanalysis because it situates the relation between aggression and sexuality in an ethical context. To convince is to collude with repression, and Lacan's pun on con-vaincre suggests that repression involves both aggression and sexuality. Yet it remains almost impossible to trace the relation between repression and aggressivity. When we enter the domain of language, where the convincing takes place, sexuality takes precedence over aggression. Emma, Ka- 
tharina, and Saint Theresa are convinced in their ecstasy that no scene of violence ever existed. Freud and Lacan agree with them, positing the primacy of unconscious sexual fantasy. Only children, for a short period, miss the point. They interpret the act of love as an act of violence. Are they too repressed to see the truth, or not sufficiently repressed?

The child's vision of violence shares certain similarities with the paranoid worldview, for the paranoid also experiences the world as aggressive and threatening. Indeed, Lacan suggests that a dimension of the self is inherently paranoid. In his thesis on paranoid psychosis, De la psychose paranoiaque, Lacan explains that paranoia is a "syntax" of social relations viewed separately from the "naive realism" of its object (387-88). This syntax consists of the paranoid's exaggerated view of social tensions, and as such psychotic violence emerges not as an arbitrary action but as an attempt to represent the world. It is an attempt both to take revenge and to fit into society because the paranoid psychotic perceives violence as reality and reality as violence.

The reality of violence is an interpretation for both the paranoid and the child. In one case, it is linked to social perception; in the other, it appears in an individual who would seem to lack social awareness. According to Lacan, however, the violence of paranoid delusion corresponds to a special relation to objects, based on a regression to secondary narcissism. At this stage, the libido is freed from objects and invested in the ego by the introjection of objects as part of the self. In a limited sense, the paranoid and child share the same view of reality. They are both imprisoned in the glass house of the mirror phase, where violence and undifferentiation reign.

For Lacan, however, the primal scene is not merely the discovery of parental intercourse. It is the stage (autre scène) used by the child to advance through the oedipal drama of sexuality and into symbolic relations. The scene works to give meaning to the affects associated with castration, language, and various images. But Lacan does not explain that the scene works principally to replace aggressivity with sexuality by establishing the identifications that lead children to represent their perception of 
aggression as a sexual episode. Neither Freudian nor Lacanian analysis can conceive of sexuality as repressive. ${ }^{10}$ At most, sexuality plays the role of an obstacle or an impasse in the individual's attempts to chart the limitations of his or her own desire.

Freud reveals in On the History of the Psycho-Analytic Movement that "the theory of repression is the corner-stone on which the whole structure of psycho-analysis rests" (14:16). It goes almost without argument that the repressed is sexuality. From the inception of his project, Freud links sexuality and repression in a special relationship. In the desire to polemicize, some analysts have noted that the contribution of psychoanalysis has been mistaken by modern thought: modern thinkers have accepted Freud's theory of repression but have repressed sexuality. They are repulsed, it is argued, not by the dynamics of the unconscious, whose formal structure they now identify with a variety of problems, but by Freud's insistence on sexuality, evident in the almost tyrannical correspondence posited between sexuality and any symbolism. In the spirit of polemics, I would respond that repression has not been accepted either by modern thought

10. It may be objected that Michel Foucault conceives of sexuality as repressive. In The History of Sexuality: Volume 1, trans. Robert Hurley (New York: Vintage, 1980), he argues that the discourse of sexuality emerging in the modern age is repressive and hardly an escape from "Victorianism," since the language of sexuality is an ordering of the drives. But Foucault does not mean that sexuality is itself repressive. Rather, the discourse of sexuality remains repressive of a pure sexuality that lies undiscovered beneath the crushing weight of pages and pages of writings on sex. Furthermore, The Use of Pleasure, trans. Robert Hurley (New York: Pantheon, 1985) reveals that sexuality and pleasure remain for the subject of ethics the objects of mastery and ascetic practice.

Nevertheless, Foucault's The Use of Pleasure does present an interesting reading of Greek homosexual ethics that has bearing on the relation between violence and sexuality. According to Foucault, sexuality was interpreted by the Greeks only in terms of an event in which someone was "penetrated." Each sexual act, therefore, requires an active and a passive agent. As long as the political hierarchy is not transgressed, sexual intercourse presents no problems. For example, when males penetrate females or slaves, the political hierarchy remains intact. But male homosexual desire represents an ethical crisis because it necessitates that the equality of the partners be disturbed: the penetration of one party by his social equal introduces a moment of violence that destroys political stability. That the Greeks conceived of some forms of sexuality as a form of violence is contrary to the theories of psychoanalysis, of course, but it also presents interesting parallels to children's sexual theories. 
or by psychoanalysis. The emphasis in psychoanalysis on the return of the repressed defines the essential dynamics of repression itself, exposing the fact that repression is by nature an idea that undoes itself. The more psychoanalysis turns its attention to this dynamic, the more repression turns into representation. The unconscious does not repress as much as it represents. And what is repressed-or, more precisely, represented-is not sexuality. The repressed is more strictly speaking sexual, by which I mean that the repressed does not have to be sexuality but that it must be fused with sexuality.

Psychoanalysis has never reached this formulation, although Lacan offers a clue to it in The Four Concepts when he insists on the "affinity between the enigmas of sexuality and the play of the signifier" (151). This new view of the unconscious ventures from Freud to Lacan and beyond to the domain of ethics. The concept of a "beyond" has a special status with regard to ethics. Indeed, there can be no ethics without moving "beyond." But we need not conceive of the place of ethics as a transcendental zone; it may refer, in opposition to traditional thought, to the most human and earthly impulses, those that structure through the pleasure principle both nature and culture. In Freud, however, the "beyond" describes the passage from the demands of the pleasure principle to the necessity of death. This fearful necessity assumes, even though Freud struggles against the idea of a death instinct, an unconscious dimension, and it restricts rather than encourages human ethics. Freud's Beyond the Pleasure Principle is the place where aggressivity catches up with sexuality and unravels the interpretive knots and temporal twists of deferred action, making the avoidance of violence an ethical impossibility. The book is Freud's least psychoanalytic and least ethical work because it makes aggression and not sexuality the interpretive mode of the unconscious.

In Lacan, it is also difficult to conceive of the sexualizing impulse of the unconscious as already being "beyond" aggressivity; one is tempted to read Freud's ethical itinerary, "Wo es war, soll ich werden," not as reducing the conflict between the ego and the unconscious but as bringing the ego to the place of unconsciousness and death. In neither Freud nor Lacan can 
the idea of the unconscious be securely united with ethics, unless ethics is radically redefined as the particular desire of an individual or reduced to a mapping of the boundaries, in the form of desire and law, of the unconscious. In psychoanalysis, the unconscious is largely a place to go beyond and not a place that is already beyond. 11

A theory of the ethical unconscious, it follows, fits only with difficulty into psychoanalytic thought. The idea of the ethical unconscious means that ethics holds sway within the desire of individuals and their communities and that the unconscious creates the necessary space to reorient the aggressive impulses detrimental to human relations. It means in the last analysis that Eros may win out over the death drive and that the sexualizing impulse of deferred action is the method of its victory. The unconscious represents cunning Death as Eros and makes it play the awkward role for as long as possible. The unconscious exercises its will through the providence of representation, of language, which clarifies and reorients the meaning of Lacan's famous phrase. The unconscious is structured like a language in its capacity to represent the world, and this linguistic structure defines its ethical status. The unconscious reproduces the same gap between sign and object that modern literary critics find in language, but here the gap reveals itself to be a safety margin, a necessary distance, a "beyond," maintained for the sake of selfpreservation. The unconscious represses aggression through the agency of sexuality; no matter how obvious the violence, when the unconscious acts upon it, we are convinced of its sexual nature. The aggression is contained by representation. Although it remains in view, it is hidden in plain sight.

Bernini's Saint Theresa is such a cover story. But it represents a cover-up not on the part of Lacan, nor on the part of psychoanalytic thought in general, but on the part of the unconscious. It illustrates admirably why the idea that repression acts only on sexuality is itself a manifestation of repression. The complaint

11. On the idea of the "beyond" and ethics, Lacan makes two rather enigmatic statements in L'Ethique de la psychanalyse. He remarks that the reality principle "is something beyond" (91) and that "ethics begins beyond" (92). 
by non-Freudians against the pansexualism of psychoanalysis is, as Freud always preached, a product of repression, but no more so than was his own preoccupation with sexuality. Both gestures find their source in the unconscious, which prefers love over violence, and life over death. The preference confounds for the better the radical insight of a child's sexual theory and the delusion of a saint. 